\title{
REVIGORAMENTO, REJUVENESCIMENTO \\ E APERFEIÇOAMENTO DO CORPO: culturas somáticas na sociedade portuguesa contemporânea ${ }^{1}$
}

\author{
INVIGORATION, REJUVENATION \\ AND PERFECTION OF THE BODY: \\ somatic cultures in contemporary portuguese society
}

Vítor Sérgio Ferreira*

\begin{abstract}
Resumo
O objetivo deste artigo é analisar as condições sociais que proporcionaram o processo de desnaturalização do corpo na história recente da sociedade portuguesa, desde o Estado Novo - regime sob o qual Portugal foi governado entre 1933 e 1974 - até a atualidade. Para tal, proceder-se-á à identificação, descrição e compreensão sociológica das diferentes culturas somáticas que informam distintas formas geracionais de usar, pensar e viver o corpo, presentes na sociedade portuguesa contemporânea. Nesta narrativa, serão tomadas como dimensões de análise as instituições mais relevantes na socialização corporal, bem como as estratégias de incorporação e os modelos de corporeidade que lhes estão subjacentes. Considerando essas dimensões analíticas, apresenta-se uma tipologia que identifica três culturas somáticas na história recente da sociedade portuguesa, as quais informam diferentes condições geracionais de usar, pensar e viver o corpo: 1) uma cultura de revigoramento físico, herdeira do Estado Novo; 2) uma cultura de rejuvenescimento físico, herdeira das culturas juvenis dos anos 1960-70 e da expansão das indústrias de design corporal nos anos 1980;3) uma cultura de aperfeiçoamento físico, herdeira da cultura biotecnológica dos anos 1990 e da radicalização da indústria de design corporal. Para além de fazer um estado da arte sociologicamente interpretado da pesquisa histórica sobre corpo feita em Portugal, o artigo sistematiza achados no âmbito de diversos projetos de pesquisa desenvolvidas desde 2002, de onde provêm as fontes históricas e entrevistas individuais que ilustram a narrativa.
\end{abstract}

Palavras-chave: História social. Cultura somática. Indústrias de design corporal. Privatização do corpo.

\begin{abstract}
The purpose of this article is to analyse the social conditions that provided the process of denaturalization of the body in the recent history of the Portuguese society, since the New State - under which Portugal was governed between 1933 and 1974 - up to present. For this, I will proceed to the identification, description
\end{abstract}

1 [N.E.] Mantivemos o estilo original do manuscrito, em português lusitano.

${ }^{*}$ Doutorado em Sociologia pelo ISCTE-Instituto Universitário de Lisboa. Investigador Auxiliar no Instituto de Ciências Sociais da Universidade de Lisboa. E-mail: vitor.ferreira@ics.ulisboa.pt 
and sociological comprehension of the different somatic cultures on the basis of distinct generational forms to use, think and live the body, in contemporary Portuguese society. In this narrative, I will take as dimensions of analysis the most relevant institutions on body socialization, as well as their incorporation strategies and corporality models. Considering these analytical dimensions, I will present a typology that identifies three somatic cultures in the recent history of the Portuguese society, which one inform different generational conditions of use, think and live the body: a culture of physical invigoration, legacy of the New State; a culture of physical rejuvenation, heritage of youth cultures of the years 60-70, and the expansion of body design industries in the years 80; and a culture of physical perfection, inheritance of the years 90 biotech culture, and the radicalisation of body design industry. In addition to a state of the art sociologically interpreted on the historical research done about the body in Portugal, the article explores findings under different research projects developed since 2002, from which come from the historical sources and individual interviews that illustrate the narrative.

Key words: social history. Somatic cultures. Industries of body design. Privatization of the body.

\section{Introdução}

Recentemente resgatado pela Sociologia às ciências da vida, essa estrutura viva e em devir que é o corpo orgânico, é também um corpo vivido, na primeira pessoa e entre outras pessoas (FERREIRA, 2013). Embora habitualmente entendido como matéria individual e natural, o corpo humano é experienciado de formas distintas não apenas devido às propriedades físicas específicas de cada um, mas também considerando os diferentes contextos sociais e culturais onde nasce, cresce, se modifica (voluntária e involuntariamente) e morre. Como constatou Boltansky nos anos 1970, a vivência do corpo é condicionada,

Em primeiro lugar pelo sistema de relações entre o conjunto de comportamentos corporais dos membros de um mesmo grupo e, em segundo lugar, pelo sistema de relações que unem aqueles comportamentos corporais e as condições objetivas de existência próprias àquele grupo (BOLTANSKY, 1975, p. 208).

É nessa perspetiva que retomo um velho conceito desse autor, o de cultura somática, enquanto sistema de regras, condutas e códigos de produção, perceção e consumo corporal específico, quer a uma formação social particular, quer às diferentes condições objetivas que estão na base dos sistemas de diferenciação e desigualdade social característicos dessa formação (classe, idade, geração, género, etnicidade etc.), com repercussão nas diversas formas de viver socialmente do corpo (BOLTANSKY, 2004, p. 135-173).

Recupero o conceito de cultura somática considerando a relevância heurística que adquire enquanto operador descritivo e compreensivo de um conjunto de associações e disjunções relativo às formas como o corpo é usado, tratado, pensado e classificado por diversos atores sociais (institucionais e informais) em determinadas formas culturais situadas no tempo e no espaço (geográfico e social). Esse conceito permite perspetivar historicamente o presente contexto de histeria do corpo (CRUZ, 2000) 
- marcado pela proliferação social de discursos, imagens, atividades e inquietações vivenciais ou institucionais sobre a dimensão carnal da vida - e ultrapassar a sua compreensão por referência a uma suposta discrição ou ausência histórica do corpo na vida quotidiana.

Com efeito, como sugerido por Neves (2004, p. 66), a presença do corpo sempre foi "espantosamente obsessiva na história do mundo ocidental". O que acontece, na verdade, é que recentemente um conjunto de processos sociais veio transformar a estrutura simbólica da cultura somática contemporânea relativamente às do passado, alterando as condições de socialização (incorporação), de reflexividade (corpo pensado) e de experiência (corpo vivido) corporal das mais jovens gerações relativamente às gerações passadas.

Em que sentido isso aconteceu? Como refere Crespo (1990, p. 8), em relação a um passado em que o corpo era assimilado a um "objeto real, existindo por si próprio, na sua materialidade biológica”, hoje, "o corpo não é um dado imutável, antes se revelando na sua historicidade, sendo a origem e o resultado de um longo processo de elaboração social". Na progressiva emancipação do corpo face à sua aparente condição natural, está implicado um conjunto de transformações estruturais de natureza sociocultural, política, económica e tecnológica, que passam pela intensa racionalização, mercantilização, individuação e privatização do corpo na recente história social.

Nessa perspetiva, o objetivo deste artigo é analisar as condições sociais que proporcionaram o processo de desnaturalização do corpo na história recente da sociedade portuguesa, desde o Estado Novo - regime sob o qual Portugal foi governado entre 1933 e 1974 - até a atualidade. Para tal, proceder-se-á à identificação, descrição e compreensão sociológica das diferentes culturas somáticas que informam distintas formas de usar, pensar e viver o corpo, formas essas que, coexistindo na sociedade portuguesa contemporânea, assumem, em grande medida, um recorte geracional. Nesta narrativa, serão tomadas como dimensões de análise as instituições mais relevantes na socialização corporal, bem como as estratégias de incorporação e os modelos de corporeidade que lhes estão subjacentes.

Considerando essas dimensões analíticas, apresento uma tipologia que identifica três culturas somáticas em presença na sociedade portuguesa contemporânea: 1) uma cultura de revigoramento físico, herdeira do Estado Novo; 2) uma cultura de rejuvenescimento físico, herdeira das culturas juvenis dos anos 1960-70 e da expansão das indústrias de design corporal nos anos 1980; 3) uma cultura de aperfeiçoamento físico, herdeira da cultura biotecnológica dos anos 1990 e da radicalização da indústria de design corporal. Passarei agora à descrição e compreensão sociológica de cada uma dessas culturas somáticas, com base num estado da arte sociologicamente interpretado da pesquisa histórica sobre corpo feita em Portugal, bem como na sistematização de alguns achados realizados no âmbito de diversos projetos de pesquisa, de onde provêm as fontes históricas e entrevistas individuais que ilustram a narrativa histórica. 


\section{Cultura de revigoramento físico}

Não descurando a imagem, os movimentos, as emoções e a energia física dos seus cidadãos, o Estado Novo - regime autoritário inspirado no fascismo e na doutrina social da Igreja Católica -, desde a sua instauração, tentou socializar, regular e disciplinar as formas de parecer, agir e expressar as apetências, os sentimentos e as capacidades corporais dos portugueses. António de Oliveira Salazar, líder do Estado Novo, concedeu ao corpo um lugar de visibilidade do seu projeto político. A manutenção do corpo individual sustentava a manutenção do corpo social, e, mesmo na mais recolhida privacidade do lar e do leito, nos mais básicos cuidados, estéticas e comportamentos, os corpos deveriam obedecer e reiterar a ordem coletiva, refletindo e engrandecendo os valores morais e políticos do regime: um ideal físico de virtude e pudor, obediência e disciplina, sobriedade e austeridade, higiene e robustez. Um corpo dedicado a Deus, à Pátria, à Família e ao Trabalho (REIS, 1990a).

No sentido de adequar o modelo corporal prescrito - puritano e austero no aspeto, humilde e cerimonioso na pose, robusto e vigoroso no movimento -, o Estado Novo muniu-se de um conjunto de instituições e mecanismos de controlo, vigilância e socialização do corpo, no sentido de docilizá-lo nas aparências, movimentos e emoções, bem como de potenciá-lo na sua força e energia (DRUMOND, 2013; GOMES, 1991). O alvo privilegiado foi o corpo dos mais jovens. Consciente de que estes poderiam ter acesso a espaços mundanos de circulação de ideias e ideais potencialmente perigosos para o regime, o Estado Novo não cedeu a exclusiva responsabilidade pela socialização dos jovens nas mãos da escola, da família ou da Igreja, e criou as suas próprias organizações para a "formação integral da juventude".

Considerando diferentes estatutos e missões físicas para os jovens corpos masculinos e femininos, criou, em 1936, a Organização Nacional Mocidade Portuguesa (MP) para rapazes e, no ano seguinte, a Mocidade Portuguesa Feminina (MPF) para moças. Essas duas organizações de juventude estabeleciam uma clara clivagem na doutrinação social de homens e mulheres e nas estratégias de adestramento dos respetivos corpos. Tal clivagem era visível, desde logo, na imposição de limites morais à exposição do corpo feminino, apertado num conjunto de interditos tanto mais severos quanto esse corpo fosse publicamente exposto. Nesse domínio, são exemplares as restrições impostas às roupas de educação física e de praia das filiadas na Mocidade Portuguesa Feminina, talhadas nos moldes da moral cristã (PIMENTEL, 2001, p. 348-349). O próprio comprimento das saias era motivo de acesa discussão na imprensa especializada da época, os seus detratores invocando razões morais e de elegância, os seus defensores, razões económicas, higiénicas e pragmáticas (CARDIM, 1998, p. 316).

A política de controlo do corpo feminino não passava apenas pela questão do recato no vestir, mas também pela regulação do exagero na postura. Essa deveria caracterizar-se pela correção e elegância dos movimentos, assim como pela contenção na expressão pública de certos gestos e expressões faciais, como rir ou 
falar alto, tagarelar ou mostrar esgares de impaciência ou desconfiança. Exigia-se às senhoritas autodomínio, polidez e discrição nos espaços de convivência social:

Uma verdadeira rapariga não usa penteados complicados, modas espaventosas, decotes exagerados. Não toma posições estudadas como "as estrelas". Não se faz interessante com gritinhos e "graças" que dão nas vistas. Uma verdadeira rapariga distingue-se pela naturalidade e correção. É a simplicidade que faz a elegância da moda e das maneiras (MOCIDADE PORTUGUESA FEMININA, 1949).

A estratégia era, portanto, invisibilizar ao máximo o corpo feminino no espaço público. Todos os indícios, expressões e adornos que pudessem provocar a captação de olhares deveriam ser evitados ou encobertos - preocupação também presente em muitos dos manuais de civilidade e cortesia da época. O corpo da "mulher de virtude" deveria ser tratado como um "templo da alma", sacralizado, conservado e guardado nos "dons" e atributos "naturais" que Deus lhe terá proporcionado. O corpo da moça era socializado sobretudo para reproduzir, para desempenhar o seu papel de "mãe de família", devendo para isso "ater-se ao espaço doméstico" e "não maquilhar, não rir, ser culta, discreta, inteligente, disciplinada, educada de maneira e de porte" (BRASÃO, 1999, p. 134).

Já o investimento político na socialização física dos corpos masculinos era orientado no sentido da exaltação da pátria. A força e a tonicidade do corpo masculino, bem como ordem e disciplina coletiva, que demonstravam quando das marchas públicas dos jovens filiados na Mocidade Portuguesa, serviam para projetar simbolicamente a força do Estado. No seu quotidiano, a expressão corporal masculina deveria transmitir a imagem do "chefe de família", clássico e sóbrio, maduro e anónimo, asseado e bem cheiroso, de cabelo aprumado e abrilhantado, fato impecável e colarinhos engomados. Não deveria ser dado a modas e a modos, sendo este um terreno deixado aos cuidados da esposa. As recomendações sobre os cuidados a se ter no masculino surgiam esporadicamente e eram feitas sobretudo em revistas femininas, tornando claro o papel da mulher enquanto responsável pela apresentação do marido.

Em suma, tanto no homem como na mulher, eram valorizadas corporeidades silenciosas, contidas e discretas ao nível da expressão gestual e imagética, regidas segundo os cânones do "bom gosto" e "bons costumes". Qualquer gesto que evidenciasse a sua presença pública poderia denunciar um excesso e tornar-se alvo de crítica, tal como o uso de adornos inúteis ou de vestuário que sublinhasse ou exibisse determinadas partes do corpo. Assim, se tentava doutrinar mais eficazmente os filhos das elites citadinas e mais escolarizadas, nem sempre dóceis, obedientes e acríticos. A pensar na socialização dos corpos dos filhos dos trabalhadores, sobretudo dos mais carenciados e, por isso mesmo, mais distantes das instâncias de controlo corporal, o regime criou também, em 1935, a Fundação Nacional para a Alegria no Trabalho (FNAT), no sentido de lhes proporcionar a prática de atividades físicas que implicassem condições de contato com o sol, o mar e o campo. 
Na medida em que os males físicos eram simbolicamente representados como sintomas de fraqueza moral e, quando propagados, de fraqueza nacional, diversas estratégias eram desenvolvidas no âmbito das instituições no sentido de transformar potenciais corpos definhados, enfezados e raquíticos em corpos robustos, corados e verticais, capazes de enfrentar quaisquer adversidades a bem da Nação: paradas, atividades ao ar livre, acampamentos, colónias de férias, banhos de mar e, sobretudo, educação física. No âmbito desta última, foi institucionalmente adotado o sistema de Ling, também vulgarmente conhecido por "ginástica sueca" (CARVALHO, 2005; CASTANHEIRA DE OLIVEIRA, 2002; CRESPO, 1977; HASSE, 2001). Tratava-se de um sistema racional de movimentos localizados e sequencialmente cadenciados, promotores da respiração, da verticalização, do aprumo e da correção do corpo. Executados em coletivos sincronizados e uniformizados de branco, sugeriam uma imagem de disciplina e ordem, de pureza física e moral, de cooperação e de exortação nacional, que esbatia e determinava as singularidades de cada corpo físico em nome do corpo social.

O objetivo de retificação corporal do regime não ia, portanto, de encontro a uma cultura física atlética, com propósitos narcísicos de satisfação pessoal, mas de uma cultura física moralizadora, no sentido de cumprir o desígnio de Juvenal: mens sana in corpore sano, "máxima essa que em salazarismo escorreito queria dizer: formação da consciência na e através da disciplina e submissão dos corpos" (GOMES, 1991, p. 109). O projeto nacional de revigoramento físico do povo tinha como móbil principal, portanto, a regeneração moral da mocidade da época, sobretudo dos jovens urbanos mais favorecidos, adeptos de um certo relaxamento de costumes ou resistência associada à vida boémia.

A cultura de revigoramento promovida pelo regime pretendia ainda zelar pela economia dos corpos. Concomitantemente a objetivos de ordem moral, as estratégias de socialização corporal empreendidas pelas instituições oficiais desenvolviam-se também no sentido de evitar o desperdício de energias desse segmento populacional em festas, divertimentos ou atos de violência. Com o incremento da educação física, pretendia-se também promover o "melhor rendimento" do "trabalho útil" dos corpos dos trabalhadores, no sentido da "diminuição das verbas orçamentais para a saúde pública" (PEREIRA, 1941).

Ainda nesse sentido, o corpo foi colonizado por várias disciplinas científicas e submetido a normas racionalizadas em termos de saúde e higiene. A ação política sobre o corpo, nessas matérias, deixa de ter um conteúdo eminentemente religioso para tomar contornos económicos, reclamando comportamentos mais racionalizados do ponto de vista do conhecimento da gestão da doença. Para esse efeito, cooperavam entre si, na vigilância e controlo dos corpos, bem como na validação científica das operações, autoridades médicas, pedagógicas e policiais, numa atuação conjunta das áreas da motricidade humana, da saúde pública e da profilaxia social.

Confrontadas com realidades sociais de extrema carência fisiológica, alimentar e civilizacional, na época, aquelas instâncias visavam à promoção da saúde pública e à melhoria das condições alimentares e de salubridade dos portugueses mais pobres. Essa maioria mal nutrida, com corpos debilitados, gretados, sujos e cansados, correspondente a cerca de três quartos da população rural em 1950: 
"assalariados rurais, pastores, ferreiros, moleiros, taberneiros, constituíam as personagens centrais de um universo dominado por uma miséria impensável” (MÓNICA, 1996, p. 220).

A promoção do "culto da água e do sabão" e a punição de "todos os que se abaixassem ao ar livre" eram objetivos aclamados pela Direção Geral da Saúde em 1950 (ANÓNIMO, 1950). Intensificaram-se também as campanhas de educação sanitária inauguradas pela Liga Portuguesa de Profilaxia Social (LPPS), com o objetivo de divulgar princípios civilizacionais de convivência e de higienização progressiva dos espaços públicos até então difíceis de penetrar na mentalidade dos portugueses. Entre as muitas campanhas realizadas pela LPPS, contam-se a "campanha de combate ao pé descalço" - aquela que foi uma das suas mais longas campanhas (1927-1965) - assim como a "campanha contra o hábito de escarrar e cuspir na via pública”, prática de tal modo legítima, segundo os códigos sociais vigentes, que "não era raro vermos pessoas de posição social, mesmo senhoras, incorrer nesta grave irreverência ao código das boas maneiras, infringindo-o censuravelmente" (LPPS, 1944).

Nesse processo de racionalização, o corpo era institucionalmente pensado e projetado como utensílio de produção. Por meio do seu conhecimento, vigilância e disciplina, em termos de hábitos de higiene, alimentação e atividade física, tentava-se promover a eficiência e o rendimento do corpo como gerador de força de trabalho. Numa sociedade em que o sistema de produção se baseava intensivamente na mão de obra humana e animal, o capital físico era o único recurso que garantia a subsistência de uma população desprovida de quaisquer outros (RAPOSO, 1991, p. 34). Mesmo para os inúmeros camponeses que, no decorrer dos anos 1950, começaram a migrar para a cidade ou para o estrangeiro, o corpo, na sua força, energia e vitalidade, continuava a ser o único capital a vender, como operários nas grandes indústrias em desenvolvimento ou como empregadas domésticas nas casas burguesas.

O valor do trabalho e do esforço físico que acarretava está na base de um certo discurso social do Estado Novo que reprovava a indolência das "classes ociosas", amantes do prazer e da vida fácil. Estas, contudo, não tinham que se preocupar com a sobrevivência; viviam mais preocupadas com as aparências. O corpo da "alta sociedade" acabava por espelhar a ideologia do regime. Muitas das suas doutrinas corporais eram adotadas para tornar visíveis as distâncias sociais. Ainda que o discurso oficial do Estado Novo reprovasse sofisticadas formas de modificação corporal, para além daquelas que promovessem a "naturalidade" e "espontaneidade" de um corpo vertical, sadio, limpo e cortês,

na verdade, o que este jogo do espontâneo não esconde é todo o trabalho incessante do "corpo social" sobre o "corpo real", uma conformação canónica aos rigores da moda, uma ânsia de transformar o destino biológico do corpo num instrumento simbólico de status, de valor (PAIS, 1990, p. 339-340).

Tendo acesso a um conjunto de recursos materiais e sociais vedado a outras camadas da população, os corpos das elites burguesas civilizavam-se por imitação dos modelos distintivos estrangeiros: quer os que eram usados por gente 
endinheirada que havia se refugiado em Lisboa, fugindo à Grande Guerra e que circulavam por entre sociabilidades exclusivas e seletivas, quer os modelos da moda internacional, sobretudo francesa, institucionalizada como paradigma do "bom gosto", "elegância" e "sobriedade", confecionados por mãos de costureiras particulares e de grandes casas de costura a partir de toiles ${ }^{2}$.

A profusão dos meios de comunicação social, no entanto, fez estender os ideais e as expectativas de "estar na moda" a camadas sociais cada vez mais largas. A popularização do cinema e, mais tarde, o surgimento da televisão, em 1957 (REIS, 1990b), tiveram o seu peso nesse processo, proporcionando a difusão de novas formas de viver e de produzir o corpo. "Estar na moda" passou a ser, para as moças "modernas", copiar não os modelos senhoris das suas mães, mas as formas sedutoras das divas de Hollywood, vistas nos ecrãs dos cinemas e nas revistas que exploravam o glamour dos corpos e das vidas dos mitos cinematográficos emergentes.

\section{Cultura de rejuvenescimento físico}

Alguma ousadia e desejo de rutura nas atitudes e cuidados com o corpo ganharam ênfase nos anos 1960 por entre os jovens mais urbanos. Estes produziam os seus corpos já não tanto por referência às instâncias socializadoras oficiais do regime, mas considerando as corporalidades mais mundanas que se davam quotidianamente a ver nas revistas, cinema e televisão.

A "mulher moderna" afirmava-se gradualmente no domínio público - em liceus e universidades, na indústria e em escritórios, em espaços mundanos como cafés ou lugares noturnos. Outrora recatadas nos seus movimentos, ocultas nas suas aparências e oprimidas nas suas emoções, muitas mulheres começaram, então, a mostrar um corpo cada vez mais vaidoso, garrido, dançante e sensual. Nas suas vivências, o prazer e a autodeterminação são possibilitados pela comercialização da pílula anticoncecional, em 1958. Nas suas aparências, existem uma descontração e uma liberdade oferecidas pela emergência do pronto-a-vestir. ${ }^{3}$

O corpo feminino raramente tinha a oportunidade de ser contemplado nu, nem mesmo na intimidade. Nos anos 1960, porém, o corpo da "mulher moderna" foi-se despindo de roupas e preconceitos, desvelando-se ao olhar alheio, na praia, na noite, na vida quotidiana. A minissaia teve um êxito estrondoso, e a imprensa feminina destacava o "novo sentido" das suas cores e formas, "espetacular" e "divertido para os olhos e para o espírito" (ANÔNIMO, 25-11-1967, p. 22-23). Para além das saias subirem bastante acima dos joelhos, os decotes ficaram pronunciados, as linhas rígidas foram abandonadas a favor de uma silhueta leve, alegre e confortável, e o uso das calças difundiu-se, marcando as formas femininas. Apesar

2 Nome dado aos moldes especiais que os costureiros franceses vendiam às modistas e aos costureiros portugueses, comprados nas grandes casas de moda parisienses.

3 [N.E.] Refere-se às roupas não mais feitas sob medida, mas àquelas produzidas em larga escala, à disposição dos clientes em lojas de confecções. 
de oficialmente interdito, no fim dos anos 1960, o biquíni começou a tomar conta das praias portuguesas. Em 1966, a revista Modas \& Bordados apresentava um anúncio publicitário da mais recente novidade, em Portugal, no âmbito da higiene feminina os tampões - para que a mulher se sentisse "livre na praia durante todo o Verão". Este anúncio é revelador de que algo estava a mudar em Portugal nas atitudes perante a exposição do corpo feminino nos espaços públicos:

o corpo descerra-se, mostra-se, exibe-se, ganhando uma nova eficácia funcional. [...] A gordura deixa, então, de ser formosura, para passar a ser uma tenebrosa preocupação para quem tem de exibir um corpo elegante e isento de massas supérfluas, não somente nos trajes de banho, como também nas toilettes de noite (PAIS, 1990, p. 340).

Os homens, por sua vez, começam também a mudar a sua imagem corporal, havendo mais propostas relacionadas ao vestuário e uma maior democratização do traje. A tradicional indústria da alfaiataria entra em crise com o surgimento do pronto-a-vestir, uma realidade que também conquista o consumidor masculino (CARDIM, 1998). Este passa ainda a assimilar tendências de moda em penteados, barbas e bigodes, que se alongam e se tornam mais espontâneos. A laca e a brilhantina, que outrora formatavam o cabelo, cedem ao desalinho de uma "moda jovem" que se afirma nacional e internacionalmente.

"A moda é hoje um fenómeno de juventude", constatava-se em 1967 (SAMPAIO, 1967, p. 26). Os anos 1960 foram, com efeito, anos de rejuvenescimento dos corpos, com a adoção de uma imagem visual mais informal e colorida por parte das gerações mais novas. O pronto-a-vestir impunha-se nas ruas e revistas de moda portuguesas, (des) cobrindo um corpo jovem que, na cidade, tinha adquirido alguma capacidade de consumo e autonomia. Um corpo que se tentava libertar dos modelos e convenções oficiais, nomeadamente das convenções de género. A moda unissexo começa a surgir, mesmo que sob acusações e lamentos de que já não se conseguiam distinguir rapazes e moças: ambos frequentavam as mesmas lojas e cabeleireiros, usavam cabelos longos ou curtos, jeans de boca de sino, blusões de cabedal, adornos variados.

A diferença individual e a rebeldia social eram valores que os corpos dos mais jovens pretendiam expressar, até por inspiração de várias "subculturas" juvenis que, em outros países da Europa e dos Estados Unidos da América eram reconhecidas por meio de indumentárias espetaculares: rock'a'billies, teddy boys, hippies, rockers e outras subculturas juvenis da época. O corpo também se libertava na dança, por intermédio de movimentos efusivos e desgarrados da presença de um par que buscava a excitação dos sentidos. O ié-ié, uma adaptação do fonema inglês yeah, representativa da Beatlemania que se sentia no país, inflamava vibrantemente os corpos que preenchiam o palco e a plateia do Teatro Monumental, em Lisboa, quer nos concursos de novos valores da música moderna, quer nos concertos de algumas estrelas internacionais que ali aconteciam.

As referências dominantes de produção da imagem corporal dos mais jovens já não passavam pela sofisticação das estrelas de cinema, mas pela irreverência 
dos astros nacionais e internacionais da canção ligeira, rock e pop que surgiam. As ondas da rádio e os ecrãs de televisão abriam-lhes horizontes para outras realidades sonoras e imagéticas, outros produtos e valores, propagando sinais de e para uma nova geração com corpos, sentidos e mentalidades diferentes do passado. Os vários estilos musicais que esses meios de comunicação difundiam, traziam consigo estilos de vestir, de dançar e de se comportar que inspiravam muitos jovens urbanos das camadas médias e altas da sociedade portuguesa.

As transformações indiciadas expandiram-se nos anos 1970, tendendo a generalizar-se após a revolução de 25 de abril de 1974. Essa foi uma conjuntura em que a sociedade portuguesa viveu transversalmente um período de exaltação revolucionária, celebrativa da liberdade social conquistada. Nos corpos engalanados de colarinhos pontiagudos libertariamente desabotoados ou de pernas escancaradas, era experimentada uma euforia coletiva a que Portugal estava pouco habituado:

O país está de pantanas, e Lisboa é o espelho deste caos que precede os novos tempos, com o coração do Rossio infestado de hippies e punks e refugiados políticos radicais [...]. Gente muito jovem, vestida de todas as cores do arcoíris, do mais escuro ao mais berrante. Rapazes e raparigas de túnicas e casacos afegãos, jeans rasgados, puídos, remendados - caríssimos e importados! -, saias compridas, mini-saia ou hot pants (GONZAGA, 2006, p. 141).

Ainda que nem tudo tivesse passado a ser permitido, muito foi reivindicado. A informação diversifica-se e muitos dos temas anteriormente tabu - como a vida sexual, o aborto ou a homossexualidade - são tratados e discutidos nos meios de comunicação social, nas escolas e na vida política, enquanto direitos sobre uma propriedade que começa a ser reivindicada como privada: o corpo. Nos anos 1980, independentemente da classe social ou do sexo, os jovens portugueses faziam-se distinguir das gerações suas predecessoras pelo fato de darem maior importância ao corpo, às atividades físicas e à vida sexual, bem como pelos gostos muito diferentes em matéria de vestuário (CONDE, 1989, p. 198-210; SCHMIDT, 1985, p. 1062).

Ao contexto de liberdade sexual herdado dos anos 1970, junta-se a vontade individual de se tornar atraente e diferente, tal como aqueles corpos mundanos com que os portugueses contactavam quotidianamente por meio da mídia e da publicidade. "Originalidade" e "estilo" são valores que atravessam as produções corporais que demarcam as novas "tribos juvenis" que emergem nos espaços urbanos portugueses. A fantasia criativa que caracteriza as modas e os modos em meados dos anos 1980 veio transformar o corpo, na maneira como é vestido, calçado, penteado ou adornado, num inestimável recurso de personalização entre as mais jovens gerações (FERREIRA, 2003, p. 341).

A moda começa a ceder ao estilo, em que o valor da diferença individual, mais do que o de distinção social, é corporalmente explorado. O absolutismo da alta-costura é derrubado com a expansão da indústria de pronto-a-vestir que, cada vez mais inventiva, assimila a variedade das tendências internacionais e torna-as mais acessíveis a um maior número de pessoas. A ditadura sazonal de uma só linha que incluía um visual completo com todos os detalhes de beleza, penteado e 
acessórios é desmultiplicada, e as normas de produção corporal assumem-se mais indicativas do que diretivas (GOMES, 2005, p.158; LIPOVETSKY, 1989a, p. 59).

A par da expansão da indústria da moda, cresce também uma indústria de design corporal que vem disponibilizar uma pletora de produtos, técnicas e serviços de manutenção corporal. Novas lojas, empresas e serviços nacionais e internacionais vêm afirmar-se no mercado português, prometendo o ajustamento aos cânones estéticos do momento e, simultaneamente, produzindo a ilusão massificada de cada um poder planear e esculpir o próprio corpo dentro de um padrão de beleza globalmente estabelecido.

Por entre a florescente indústria de design corporal, crescem as iniciativas comerciais de atividade física, quer ao nível do investimento em produtos para utilizar em espaço doméstico - desde sistemas de exercícios, periódicos especializados, roupa e calçado, até equipamento caseiro diverso -, quer ao nível do investimento em espaços coletivos (FERREIRA, 2011a). Esses espaços começaram por assumir a forma de ginásio "de bairro" nos anos 1980, onde as pessoas acediam a modernos equipamentos ergonómicos onde podiam exercitar individualmente o seu corpo ou exercitá-lo coletivamente experimentando novas e apelativas atividades físicas de grupo importadas dos EUA, como a ginástica aeróbica, a par de outras modalidades que foram sendo criadas e importadas sob o conceito de body training systems ou group fitness programs ${ }^{4}$.

Posteriormente, nos anos 1990, os "ginásios de bairro" viram-se ameaçados pelos health clubs, espaços multifuncionais depositários de valências diversas nas áreas da estética, da saúde, da alimentação e do lazer corporal, muitos deles representantes de cadeias internacionais que se instalaram em algumas das principais cidades portuguesas. O processo de crescimento e de diversificação comercial das atividades físicas indoor beneficiou-se de uma conjuntura económica favorável, caracterizada pelo aumento do poder de compra da população portuguesa e pela melhoria das condições de vida de alguns dos seus sectores e grupos sociais, nomeadamente das suas classes médias. A proliferação de ginásios e health clubs foi ainda favorecida pelo prolongamento quer da esperança média de vida, quer dos processos de escolarização e de transição para a vida adulta, dinâmicas que fizeram dos aposentados e jovens estudantes dois públicos-alvo fundamentais desses espaços.

O paradigma higienista da "mente sã em corpo são" deu lugar a outros mais imagéticos, ilustrados pelas máximas "look good, feel good" ou "be some body". "Estar em forma" implica mostrar (determinadas) formas. A manifestação mais valorizada do "corpo saudável" deixa de ser o seu rendimento, força e resistência, para passar a ser a sua aparência. A saúde cosmetiza-se e torna-se num fenómeno estético: não basta mantê-la, mas fazer transparecê-la, nomeadamente por meio da conservação de uma imagem corporal rejuvenescida:

4 Como o body pump, body balance, body combat, body step, body attack, body jam, body jump ou o spinning - RPM. 
Se os ginásios de "educação física" tinham como vocação disciplinar o corpo para formar melhores cidadãos, mais saudáveis e competentes, preparandoos para os desafios das novas sociedades surgidas com a industrialização, os atuais health clubs, por seu lado, associam a juventude, a beleza e a saúde do corpo à auto-confiança, à auto-estima e ao bem-estar, oferecendo produtos e serviços destinados a "moldar o corpo" à medida das necessidades culturais e preocupações de cada indivíduo (FORTUNA; FERREIRA; DOMINGUES, 2002, p. 54).

Com efeito, toda a panóplia de produtos, serviços e técnicas disponibilizada pela florescente indústria de design corporal acena com promessas mercantis de rejuvenescimento dos corpos, alimentando a mitologia de um eterno "corpo jovem", atraente, saudável e enérgico. Promovida a valor de referência e reverência, esta corporeidade corresponde a um imaginário corporal que se materializa no desejo de obter uma tensão máxima da pele e uma silhueta conforme a biologia juvenil; de manter um corpo ativo e sempre apto, longe da ameaça de doença ou do prenúncio de morte; de construir um corpo sedutor e sensual, sempre desejável e ávido; de explorar um corpo hedonista e desejante, que proporcione gozo e prazer imediato.

$\mathrm{O}$ "corpo jovem" assomou como realidade ideal(izada), passando a alimentar ansiedades e expectativas de muitos, jovens e menos jovens. As atitudes e práticas corporais cultivadas pelos mais jovens de facto refletiram-se na vivência corporal da geração dos pais, pressionados no sentido da manutenção da jovialidade dos seus corpos: "operou-se uma inversão maior nos modelos de comportamento", diz Lipovetsky, justificando essa afirmação com as palavras de Yves Saint-Laurent: "outrora, uma rapariga queria parecer-se com a mãe. Atualmente, é o contrário que se verifica". E, nesta ótica, "o culto da juventude e o culto do corpo caminham a par" (LIPOVESTKY, 1989b, p. 166).

Pode-se assim afirmar que a cultura de rejuvenescimento do corpo emerge, em grande medida, do processo de mercantilização que a produção social do corpo passa a exigir. O capitalismo continua a obra de colonização do corpo humano enquanto recurso a ser capitalizado, mas agora em progressiva emancipação da penosidade do trabalho braçal e dos constrangimentos físicos do dever laboral. Entrega-se às férias e aos tempos livres próprios de uma sociedade de consumo, ao sport, sun, sex and sea (SANT'ANNA, 2001, p. 58), ao culto do prazer, do bem-estar, da boa forma, um corpo que se deseja (e é desejado) sem calos e signos de trabalho, jovem, atraente, atlético, saudável, energético.

Nesse contexto, o corpo pós-democrático passa a ser socialmente investido e valorizado não como corpo produtivo mas como corpo produzido, "o mais belo, precioso e resplandecente" de todos os objetos de consumo (BAUDRILLARD, 1975, p. 212). Ao mesmo tempo em que perde o seu valor funcional como utensílio gerador de força de trabalho, cresce o seu valor simbólico como acessório de presença de si no mundo (LE BRETON, 1999, p. 42), o signo cultural mais estreitamente associado à pessoa e à expressão da sua identidade pessoal, demarcando e distinguindo socialmente cada indivíduo enquanto sujeito uno e único (FERREIRA, 2008a). 
O corpo vislumbra-se, assim, emancipado da sua suposta "condição natural". No contexto das inúmeras possibilidades de produção e modificação corporal disponibilizadas, o corpo passa a ser socialmente pensado e vivido já não como um destino herdado e intocável, mas como um recurso projetado e modificável, sujeito a atos de vontade que expressam expetativas e desejos identitários do seu proprietário, dentro da diversidade de possibilidades de design corporal no momento, bem como da desigualdade de possibilidades materiais para lhes aceder:

em tempos pensado como sendo locus da alma, depois como centro de necessidades obscuras e perversas, o corpo tornou-se mais disponível para ser "trabalhado" pela influência da modernidade tardia e, como resultado destes processos, as suas fronteiras alteraram-se. Todo o seu exterior, ou o que é visível, tornou-se permeável às "ofertas" emanadas da sociedade (GIDDENS, 1997, p. 201).

\section{Cultura de aperfeiçoamento físico}

As condições de socialização, uma, segmentada e sofisticada indústria de design corporal cada vez mais diversa, em cumplicidade com canais mediáticos cada vez mais especializados em matérias corporais, criam a ilusão social de omnipotência do indivíduo sobre o corpo, tanto na sua aparência exterior como no seu próprio funcionamento interno. Essa ilusão, porém, hoje em dia, vai muito além dos anseios e expetativas de conservação de um eterno presente. Mais do que apenas o rejuvenescimento do corpo, sonha-se com o seu aperfeiçoamento. Ao imaginário de "corpo jovem" sobreleva-se o ideário de "corpo perfeito" como corporeidade de referência e reverência.

De fato, os bens, serviços e as tecnologias recentemente disponibilizados pela indústria de design corporal que já não atuam apenas ao nível mais superficial e holista do corpo no sentido da sua manutenção - como os sistemas de atividade física disponíveis nos anos 1980 - mas introduzem a hipótese da sua correção por meio de técnicas e produtos cada vez mais focalizados, pormenorizados e invasivos das fronteiras interiores do corpo. A produção e a modificação corporal já não acontecem apenas no seu todo e de forma padronizada, mas, cada vez mais, nas suas mais infimas partes (SEALE; CAVERS; DIXON-WOODS, 2006; SHARP, 2000; SHEPER-HUGHES, 2001). Nesse contexto, o corpo contemporâneo é pensado e vivido cada vez mais como uma realidade passível de ser construída, fabricada, "um kit, uma soma de partes eventualmente destacáveis à disposição do indivíduo" (LE BRETON, 1999, p. 24), cada uma impelindo a formas especializadas de consumo no sentido de conseguir corresponder aos ideais de perfetibilidade de cada corpo.

O crescimento exponencial da indústria de design corporal hoje, vai efetivamente muito além do "império das vaidades" das modas e da cosmética, com a medicina, as ciências da nutrição e da motricidade, a tecnologia e a engenharia genética, entre outras áreas, a associarem-se na produção de uma multiplicidade de técnicas e tecnologias que invadem cada vez mais o corpo na sua vida quotidiana. 
Os recursos que a atual indústria de design corporal desenvolve e disponibiliza no mercado compreendem esferas cada vez mais diversas, com produtos cada vez mais diversificados, criativos e personalizados.

No segmento do bem-parecer, a par dos produtos cosméticos que atuam na superfície da pele, desenvolve-se todo um conjunto de recursos dietéticos, químicos e biológicos que intervém nos processos biológicos e mecanismos internos do corpo, no sentido de modificar formas e silhuetas corporais (dietas específicas, suplementos alimentares, diuréticos, esteroides-anabolizantes etc.); à joalharia e à maquiagem, que decora efemeramente sobre a pele, junta-se outra que a invade permanentemente, como as tatuagens e vários tipos de bodypiercing; nas academias e health clubs, os sistemas de exercícios coletivamente realizados e padronizadamente coreografados articulam-se com serviços que assumem formas de resposta personalizada perante ambições, problemas, riscos e características fisiológicas e morfológicas de cada corpo, com a proliferação da figura do personal trainer ${ }^{5}$; a cirurgia plástica populariza-se no sentido de "corrigir" ou valorizar partes específicas do corpo, muito além da renovação ou esticamento da epiderme no sentido de disfarçar as marcas da idade ${ }^{6}$; os desenvolvimentos nos campos da genética e da biotecnologia abrem a possibilidade de se agir diretamente sobre a fórmula celular dos tecidos e/ou órgãos dos sujeitos.

A par do segmento da indústria de bem-parecer, desenvolve-se o segmento do bem-fazer corporal, constituído por bens, serviços e tecnologias que afiançam os elevados padrões de desempenho, saúde e vitalidade exigidos ao corpo humano na sociedade contemporânea, que se quer sempre dinâmico e ativo: bebidas e produtos energéticos que possibilitam enfrentar um estilo de vida cada vez mais acelerado; químicos que se tomam ora para dormir, ora para acordar, ou que asseguram longos períodos de atividade, aumentando a capacidade de esforço e vencendo a fadiga ou o sono; produtos que aperfeiçoam a memória ou garantem a obtenção de um melhor desempenho e rendimento sexual, verdadeiros elixires do alongamento e do prolongamento... Esses são algumas das próteses farmacológicas ou "naturais" hoje disponíveis para corrigir e regular cada corpo, considerando as necessidades de desempenho para enfrentar os desafios do mundo contemporâneo.

Por último, desenvolve-se ainda uma esfera dedicada ao bem-estar corporal, que compreende produtos, serviços e tecnologias que, muito além da preocupação higienista com o asseio, prometem o prazer e a satisfação pessoal por meio do corpo: toda uma gama de acessórios que prometem o relaxamento e a estimulação

5 Um profissional da atividade física requisitado para fazer um programa de treino adequado a determinado corpo particular e acompanhar individualmente a sua execução, símbolo por excelência do egobuilding (LIPOVETSKY, 1994, p. 129).

6 Veja-se, por exemplo, o artigo de Rodrigues (2012) sobre a cirurgia plástica nas vaginas, onde a preocupação com a melhoria de determinadas funções fisiológicas terá sido ultrapassada pela preocupação com a estetização morfológica do órgão, reconfiguração motivacional que será transversal à cirurgia plástica hoje realizada em muitos outros órgãos do corpo humano. 
prazerosa dos sentidos (velas, sabões, óleos essenciais e espumas de banho perfumadas); terapias diversas colocadas ao serviço do corpo ou nele ancoradas ao serviço da psiquê, como spas, terapias bioenergéticas e de meditação, bem como os inúmeros tipos de massagens ou outras atividades de importação oriental; ou as próteses farmacológicas que regulam, dominam e/ou transformam o humor, isto é, a tonalidade emocional da relação do indivíduo com o mundo, quer em contexto de mal-estar patológico, como os antidepressivos e ansiolíticos, quer em contextos lúdicos, como muitas substâncias psicotrópicas hoje consumidas entre jovens (LE BRETON, 1999, p. 53-58).

A par do desenvolvimento da indústria de design corporal, em grande parte suportando-o e promovendo-o, emerge também na sociedade portuguesa uma crescente tematização e difusão mediática de imagens e informações sobre corpo, não só por meio da publicidade, mas também de outros formatos jornalísticos:

revistas, programas e canais temáticos de televisão, jornais, publicidade e debates médicos públicos difundem informações mais ou menos especializadas sobre alimentação e exercício físico, apresentando soluções que prometem a saúde física e psicológica ou a transformação do corpo (GOMES, 2005, p. 152).

Esbatendo a fronteira entre ficção e realidade, as mensagens midiáticas desses meios especializados tendem a difundir a convicção de que, seguindo à risca as instruções de um determinado produto ou serviço, é possível atingir o ideal de perfetibilidade corporal ambicionado. Ao mesmo tempo, tornam os indivíduos mais conscientes da sua aparência externa e mais reflexivos sobre ela, confrontandoos com ícones que enformam (e conformam) ideais de perfeição física, "corpos de sonho" que saem do reino da exceção e invadem a vida quotidiana.

Ao explorar largamente imagens corporais que estabelecem elevados padrões de atratividade e desempenho corporal, a ação da mídia e do mercado potenciam sentimentos de insatisfação e incompetência física na imagem que cada um desenvolve sobre o próprio corpo: em Portugal, na viragem do milénio, mais de $1 / 3$ dos jovens entre 15 e 29 anos manifestava o seu desejo em melhorar a sua forma e aspeto físico, sendo cerca de $20 \%$ a proporção daqueles que afirmavam sentir com regularidade (muitas ou algumas vezes) não gostar do seu corpo tal como é (FERREIRA, 2003, p. 275-280).

Esses são efeitos que se materializam, entre outros comportamentos, na intensificação de estratégias de vigilância sobre as formas e funções do corpo, bem como, muitas vezes, numa gestão corporal "de risco", quando a adesão a determinadas práticas de modificação corporal, como as dietas ou a atividade física, por exemplo, é feita de uma forma radicalizada (FERREIRA, 2011b). É nesse contexto que alguns comportamentos tidos como distúrbios de natureza psicopatológica têm aumentado na sociedade portuguesa, nomeadamente entre os mais jovens, como a anorexia ou a vigorexia. 
Contava-me a V., uma jovem de 28 anos, acerca da anorexia que viveu entre os 15 e os 22 anos $^{7}$, que:

Tinha tudo um bocadinho a ver com o ideal de perfeição. Porque tudo rodava em função disso, o ser a melhor aluna, o ser perfeita no corpo, tinha tudo a ver com esse padrão. Portanto, eu era a melhor aluna, era elogiada porque escrevia bem, e falta-me uma coisa que era ser bonita, ser perfeita. Como as modelos que via na televisão e essas coisas todas, como algumas amigas minhas que não se esforçavam minimamente e que eram como eu gostava de ser.

Explicava-me o B., um jovem de 28 anos, praticante de musculação, a propósito do corpo hipermusculado que cultivava desde os 19 anos: $^{8}$ :

Comecei a tomar suplemento, uma proteinazinha, uma creatinazinha. Entretanto, falaram-me sobre os esteroides anabolizantes, e eu tentei experimentar... [...] Espetacular, mesmo! Uma pessoa atinge mesmo um nível... mesmo muito bom! É uma qualidade brutal! Por isso é que dizem que a malta que começa a fazer essas coisas, depois aquilo tornam-se vícios. [...] Eu vicieime naquilo. Viciei-me mesmo em ginásio... Se não fosse, para mim era como uma doença... Tinha que ir treinar... Era mesmo obcecado com aquilo... [...] Tinha um objectivo, queria ficar grande. E fiquei! [...] O (corpo) ideal era... sim, o objetivo era chegar àquele corpo como o dessa malta que a gente vê aí, nessas revistas, sei lá, todo tratado... [...] Tipo o Schwarzenegger, por exemplo, que foi Mister Universo...

É nesse contexto que os usos de muitas das técnicas de modificação do corpo hoje disponíveis no mercado, ou os resultados corporais que permitem, são socialmente percecionados, sobretudo entre as mais velhas gerações, como "abusos" do corpo, "excessivos", "exagerados", "extremos", "desnecessários", "mutilações" ou "desfigurações" corporais realizadas em nome de motivações estéticas supostamente superficiais e fúteis. No entanto, quando adornam a sua pele com tatuagens ou piercings, tomam anabolizantes ou fazem dietas radicais para modificar a sua silhueta, só para dar alguns exemplos sobre os quais pesquisei (FERREIRA, 2008b, 2011a), mesmo que incorram em riscos, os jovens fazem-no convictos de que estão no pleno exercício de um direito fundamental: o usufruto sobre um patrimônio

7 Entrevista individual coletada no âmbito do projeto de investigação «Corporeidades HiperDisciplinadas: vivências e sentidos juvenis», desenvolvido entre 2007 - 2012 para o Pós-Doutoramento no Instituto de Ciências Sociais da Universidade de Lisboa, com bolsa financiada pela Fundação para a Ciência e a Tecnologia (REF. SFRH/BBD/27158/2006).

8 Entrevista individual coletada no âmbito do projeto de investigação «Corporeidades HiperDisciplinadas: vivências e sentidos juvenis», desenvolvido entre 2007 - 2012 para o Pós-Doutoramento no Instituto de Ciências Sociais da Universidade de Lisboa, com bolsa financiada pela Fundação para a Ciência e a Tecnologia (REF. SFRH/BBD/27158/2006). 
individual que percecionam como sua propriedade privada e sobre a qual entendem ter plena autoridade.

Afirmava-me calorosamente o M., um jovem de 25 anos cujo corpo estava coberto de tatuagens ${ }^{9}$ :

Ninguém me poderá dizer o que é que eu faço ou o que é que eu deixo de fazer com o meu corpo! É meu, acima de tudo! Não é da minha mãe, não é do meu pai, que são os responsáveis por eu estar vivo. Eles muito menos são aqueles que poderão controlar o que eu faço ou não faço. Apenas eu, mais ninguém, pode dizer o que é que eu faço com o meu corpo!

Descrevia-me também a este propósito a A., uma jovem de 24 anos, estudante de medicina que, desde a adolescência, desenvolve um quadro de restrição alimentar que ela própria conota com a anorexia, nunca havendo sido diagnosticada e acompanhada clinicamente ${ }^{10}$ :

Eu achava sempre que estava a controlar tudo [no processo de emagrecimento] [...]. Achei que tinha de controlar aquela maneira de estar e aquele peso [que tinha]. [...] Achava que queriam controlar-me, mas que ninguém me ia controlar, porque eu controlava-me a mim própria. [...] Achei que não iam ter mais domínio sobre mim, porque eu é que sabia aquilo que queria e ia para a frente com isso. [...] E pensamos que estamos a controlar, mas não estamos.

No frenesim da adequação a um “corpo perfeito", esses jovens sujeitam voluntariamente o seu corpo a regimes quase sacrificiais de desporto ou restrição alimentar na ilusão de estarem a dominar mecanismos biológicos. E baseados no sentimento de controlo do seu próprio corpo, esses jovens constroem um sentimento subjetivo de empoderamento sobre o seu corpo e a sua identidade. Uma ficção que, não raras vezes, vem questionar a própria sustentabilidade biológica e pôr em risco o equilíbrio homeostático do organismo. Modificar o corpo configura, assim, uma tomada de posse de si próprio sobre si mesmo, celebrando perante os outros o poder de (auto)determinação e (auto)controle sobre a sua própria ação - poder esse que os jovens sabem frágil e vulnerável perante os condicionamentos que lhes são impostos na sociedade contemporânea. Os depoimentos mostram-nos como, de facto, muitos jovens encontram no corpo o lugar performativo de expressão e desempenho de um

\footnotetext{
9 Entrevista individual coletada no âmbito do projeto de investigação «Expressões 'Radicais' do Corpo em Contextos Juvenis», desenvolvido entre 2002 - 2006 para o doutoramento no ISCTE-IUL, com bolsa financiada pela Fundação para a Ciência e a Tecnologia (REF. SFRH/BD/5264/2001).

10 Entrevista individual coletada no âmbito do projeto de investigação "Corporeidades HiperDisciplinadas: vivências e sentidos juvenis», desenvolvido entre 2007 - 2012 para o Pós-Doutoramento no Instituto de Ciências Sociais da Universidade de Lisboa, com bolsa financiada pela Fundação para a Ciência e a Tecnologia (REF. SFRH/BBD/27158/2006).
} 
ideário de liberdade e autonomia individual, face a formas de controlo social a que estão sujeitos na sua vida quotidiana.

Os sentidos investidos nos usos de estratégias de aperfeiçoamento do corpo não são de ordem meramente estética, mas também emancipatória. São usos e abusos do corpo que vêm muitas vezes no sentido de desafiar as instâncias que, em vários domínios da vida social (familiar, escolar, profissional, médico, jurídico etc.), estão tradicionalmente autorizadas a exercer o poder de produzir e regular a figura e o gesto corporal. O corpo surge, assim, capitalizado como um património individual na luta do sujeito pelo seu lugar no mundo, pelo controlo sobre si próprio e a sua vida.

Esse é, aliás, um dos principais traços que marcam a cultura somática contemporânea, demarcando a novidade da atual civilização do corpo relativamente ao passado. Decorre, em grande medida, um processo estrutural que designo de privatização social do corpo, ocorrido ao longo da segunda metade do século XX na sociedade portuguesa (FERREIRA, 2011c), tal como em muitos outros contextos das sociedades ocidentais contemporâneas. Quer isso dizer que, em termos de reflexividade e vivência do corpo, ao mesmo tempo que se assiste à sua gradual exposição e desnudamento no espaço público, bem como à sua aparente liberalização de uso e mesmo de abuso, o corpo vem sendo socialmente entendido como um bem privado e individual, uma propriedade sobre cuja intervenção, opções e escolhas cada pessoa entende ter pleno direito e autoridade individual.

Tal não aconteceu sem controvérsia. Um conjunto de lutas sociais surgiu no sentido da reivindicação do poder de autodeterminação e controlo pessoal sobre o corpo próprio, nomeadamente contra o Estado. Se algumas dessas lutas ficam pela informalidade de manifestações e reações individuais limitadas ao mundo de vida de cada um, outras vieram a adquirir formas de cidadania mais amplas e organizadas, desenvolvidas no âmbito de associações ou movimentos sociais (como os movimentos feministas, ou os movimentos LGBT, por exemplo), até chegar às agendas dos partidos políticos.

As causas têm sido diversas como o "direito" à contraceção e ao aborto, ao prazer e a uma sexualidade livre, ao aluguer ou à venda de órgãos, tecidos e fluidos corporais, à livre modificação de qualquer parte do corpo - desde a colocação de um simples piercing ou tatuagem, à alteração cirúrgica dos seus órgãos -, até à reivindicação limite de tirar a vida ao corpo apelando ao reconhecimento legal de figuras jurídicas, como o "testamento vital" ou a "eutanásia", quando as condições físicas e/ou mentais do indivíduo não lhe permitem exercer a vontade sobre si próprio.

Por outro lado, considero ainda que o processo de privatização do corpo não é consubstanciado apenas nas lutas pela reivindicação pelos direitos ao livre uso, expressão e autoridade individual sobre ele. Repousa ainda sobre uma dinâmica coletiva de responsabilização individual sobre o corpo próprio, organizadora de uma nova economia psíquica que tende à regulação íntima das emoções, das maneiras e das aparências. Se cada um, à partida, tem pleno direito sobre o seu corpo, é igualmente responsável pelo cumprimento de um conjunto de deveres sociais sobre esse bem. Deveres que passam não apenas por cuidar da respetiva aparência, 
vitalidade e humor, mas também zelar pela respetiva duração e qualidade de vida, assumindo um papel preponderante no controlo e na identificação atempada dos sintomas de patologias diversas (cancro, problemas cardiovasculares etc.), na prevenção de condutas de risco (nomeadamente por meio da redução do álcool e do tabaco, da obrigatoriedade do exercício físico ou de sexo protegido), ou no evitamento de excessos (alimentares, de exposição ao sol, de medicalização etc.).

Assim, se à primeira vista o processo de privatização do corpo parece corresponder a um progressivo desaparecimento dos interditos normativos, descobre-se que, na realidade, é expressão de uma nova e mais subtil distribuição social dos constrangimentos e das disciplinas corporais, porque voluntária, desmultiplicada e discreta. As sucessivas formas de liberação corporal que têm vindo a acontecer traduzem não um eclipse dos constrangimentos exteriores sobre o corpo, mas o seu deslocamento para a esfera individual, operando por meio de mecanismos mais impercetíveis, sedutores e eficazes de interiorização e reprodução de novas normas e padrões corporais.

\section{Conclusão}

Embora discreta, a luta pelo controlo sobre os significados, comportamentos e prazeres do corpo tem sido crucial nas últimas décadas, ou não fosse o corpo o lugar onde o social é mais convictamente representado como individual e as políticas mais bem disfarçadas enquanto natureza. Era este o projeto político da cultura de revigoramento físico empreendido pelo Estado Novo: construir um corpo disfarçado de "naturalidade" que espelhasse os seus valores mais profundos e agisse na conformidade e no interesse do regime. Um corpo pensado e vivido como utensílio a cuidar enquanto força de trabalho, socialmente valorizado pelo rendimento laboral que proporciona e como instrumento de expressão moral de um coletivo, socializado na dependência de um projeto coletivo nacionalista, e vigiado segundo padrões ético-morais muito estritos e conservadores.

Os espaços de socialização diretamente criados e controlados pelo poder (a escola e as mocidades portuguesas, masculina e feminina, em aliança com as instituições de formação religiosa) cultivavam o corpo como um espaço de interdições, sagrado, intocável, apenas retificável na medida do que se entendia ser a sua "naturalidade": um corpo discreto, asseado e saudável, pronto para servir ao Estado no trabalho, na reprodução e na moral da época. Para tal, recorreu à respeitabilidade dos conhecimentos e da ação de profissionais da medicina, da educação física e da religião, como forma de habituar o corpo dos portugueses a novas modas e modos. Esses agentes procederam a um trabalho de correção e de vigilância em consonância com um conjunto de valores políticos e sociais, segundo estratégias diferenciadas em função de públicos muito definidos: as gentes simples dos campos, as gentes viciosas e ociosas das cidades, a mocidade ameaçada por tentações de vária ordem.

Desde meados do século XX, porém, que forças sociais diversas, não só políticas (como o movimento feminista), mas também mundanas (como o mercado 
e os meios de comunicação social), começaram a sujeitar o corpo a um trabalho de desnaturalização, emancipando-o da postura que o tomava como destino geneticamente herdado que apenas urgia manter na sua vitalidade. Nas condições sociais, culturais e económicas herdadas pelo 25 de Abril, o corpo, na forma como é conservado, rejuvenescido ou aperfeiçoado, converteu-se num importante acessório de presença de reconhecimento social do indivíduo no mundo, projetável segundo o seu desejo, empenho e recursos. Um património privado que cabe a cada um explorar, gerir e capitalizar o melhor que puder e souber, considerando os novos imperativos estéticos e éticos determinados pelos mercados do bem-parecer, bemfazer e bem-estar.

Se, sob a égide da cultura de revigoramento físico, o controlo dos excessos nos gestos, nas aparências e nas emoções era claramente realizado por meio da ação de instituições como a polícia, a medicina, a religião ou a escola, encarregues de fazer aplicar e vigiar os múltiplos interditos corporais institucionalizados, a cultura de aperfeiçoamento do corpo responsabiliza o próprio indivíduo por essa mesma regulação e controlo, em constante atenção sobre a sua apresentação, forma, desempenho e disposição. Os indivíduos são responsavelmente convidados a disfarçar marcas de envelhecimento, a erradicar sintomas de degradação física, a melhorar ou a conservar a forma, a corrigir defeitos, a melhorar desempenhos e humores. Perpetuamente submetido ao olhar de si próprio sobre si mesmo, constantes estratégias de autovigilância e autodisciplina são por ele "naturalmente" assumidas, incorporadas e transformadas em automatismos e obrigações a cumprir na esfera da vida privada, frequentemente sob o epíteto de "estilo de vida saudável". E assim, esse tal corpo publicamente apresentado como pessoal e livre descobre-se, afinal, um corpo privadamente socializado e disciplinado.

\section{Referências}

ANÓNIMO. As linhas com que se cose Mary Quant. Magazine Semanário Feminino, n. 51, p. 22-23, 25 de novembro de 1967.

ANÓNIMO. Cartilha de sanidade para a conduta do povo português. Lisboa: Serviços de Saúde e Assistência Social, 1950.

BAUDRILLARD, J. A sociedade de consumo. Lisboa: Edições 70, 1975.

BOLTANTSKY, L. Les usages sociaux du corps. Annales: économies, sociétés, civilisations, v. 26, n. 1, p. 205-233, 1975.

As classes sociais e o corpo. São Paulo: Paz e Terra, 2004.

BRASÃO, I. Dons e disciplinas do corpo feminino: os discursos sobre o corpo na história do Estado Novo. Lisboa: Comissão para a Igualdade e para os Direitos das Mulheres, 1999.

CARDIM, V. C. Fashion, design, cultura e identidade: a costura social da moda em Portugal no século XX. 1998. Tese (Doutorado em Antropologia Cultural e Social) - Universidade Nova de Lisboa, Faculdade de Ciências Sociais e Humanas, Lisboa, 1998.

CARVALHO, L. M. Explorando as transferências educacionais nas primeiras décadas do século XX. Análise Social, v. 40, n. 176, p. 499-518, 2005. 
CASTANHEIRA DE OLIVEIRA, J. A educação física na escola primária do Estado Novo. Coimbra: Edições Tenacitas, 2002.

CONDE, I. A identidade social e nacional dos jovens. Lisboa: Instituto de Ciências Sociais; Instituto da Juventude, 1989.

CRESPO, J. História da educação física em Portugal: os antecedentes da criação do INEF. Ludens, v. 2, n. 1, p. 45-52, 1977.

. A história do corpo. Lisboa: Difel, 1990.

CRUZ, M. T. A histeria do corpo. Revista de Comunicação e Linguagens, n. 28, p. 363-375, 2000.

DRUMOND, M. Ao bem do desporto e da nação: relações entre esporte e política no Estado Novo português (1933-1945). Revista Estudos Políticos, n. 7, p. 298-318, 2013.

FERREIRA, V. S. Atitudes dos jovens portugueses perante o corpo”. In: PAIS, J. M. \& CABRAL, M. V. Condutas de risco, práticas culturais e atitudes perante o corpo. Oeiras, Celta Editora, p. 265-366, 2003.

V. S. Be some body: modificação corporal e plasticidade identitária na sociedade contemporânea. In: CABRAL, M. V., WALL, K., ABOIM, S. \& CARREIRA DA SILVA, Filipe. Itinerários. A investigação nos 25 anos do ICS. Lisboa, Imprensa de Ciências Sociais, p. 671-689, 2008a.

V. S. Marcas que demarcam: tatuagem, body piercing e culturas juvenis. Lisboa, Imprensa de Ciências Sociais, 2008b.

V. S. Pesos, halteres e sentidos dos corpos (h)alterados: um século de musculação em Portugal. In: NEVES, J. \& DOMINGOS, N. Uma história do desporto em Portugal. v. III, Vila do Conde, Quidnovi, p. 231-257, 2011a.

, V. S. O 'jovem radical' contemporâneo: novos sentidos de um qualificativo juvenil. Crítica e Sociedade. Revista de Cultura Política. v. 1, n. 2, p. 107-127, 2011 b.

, V. S. Modas e modos: a privatização do corpo no espaço público português. In: NUNES DE ALMEIDA, A. História da vida privada em Portugal: os nossos dias. Lisboa, Círculo dos Leitores, p. 242-276, 2011c.

, V. S. "Resgates sociológicos do corpo: esboço de um percurso conceptual”. Análise Social. v. 48, n. 208, p. 494-528, 2013.

FORTUNA, C.; FERREIRA, D.; DOMINGUES, M. Cultura, corpo e comércio: tendências socioculturais relacionadas com a estética e o bem-estar. Lisboa: Observatório do Comércio, 2002.

GIDDENS, A. Modernidade e identidade pessoal. Oeiras: Celta, 1997.

GOMES, R. Poder e saber sobre o corpo: a educação física no Estado Novo (1936-1945). Boletim da Sociedade Portuguesa de Educação Física, n. 2-3, p. 109-136, 1991.

. Novos corpos para novas personagens: ensaio sobre a 'manutenção da forma' e o cuidado de si.

Boletim da Sociedade Portuguesa de Educação Física, n. 30, p. 151-162, 2005.

GONZAGA, M. António variações: entre Braga e Nova Iorque. Porto: Ancora Editora, 2006.

HASSE, M. O outro corpo. Ingrid de Figueiredo (Fröken) e o desenvolvimento da educação física em Portugal (1938-1981). Ex Aequo, n. 4, p. 41-56, 2001.

LE BRETON, D. L’adieu au corps. Paris: Métailié, 1999.

LIPOVETSKY, G. A era do vazio: ensaio sobre o individualismo contemporâneo. Lisboa: Relógio D’Água, 1989a.

O império do efémero. Lisboa: Dom Quixote, 1989b.

O crepúsculo do dever: a ética indolor dos novos tempos democráticos. Lisboa: Dom Quixote,

1994.

LPPS - Liga Portuguesa de Profilaxia Social. Escarrar, cuspir: um hábito perigoso e nojento. Porto: Edições LPPS, 1944. 
MOCIDADE PORTUGUESA FEMININA. Menina e moça, n. 24, 1949.

MÓNICA, M. F. A evolução dos costumes em Portugal, 1960-1995. In: BARRETO, A. (Org.). Situação social em Portugal: 1960-1995. Lisboa: Imprensa de Ciências Sociais, 1996, p. 215-231.

NEVES, H. Ausência presença do corpo na cultura ocidental: o corpo (des) apropriado. Manifesto, n. 5, p. 66-78, 2004.

PAIS, J. M. Austeridade e moralismo dos padrões estéticos. In: REIS, A. (Org.). Portugal contemporâneo (1926-1958). Lisboa: Alfa, 1990. v 6. p. 349-352.

PEREIRA, C. M. Problemas da Mocidade Portuguesa. Angra do Heroísmo: Tipografia Angrense, 1941.

PIMENTEL, I. F. História das organizações femininas no Estado Novo. Lisboa: Círculo de Leitores, 2001.

RAPOSO, P. Corpos, arados e romarias. Lisboa: Escher, 1991.

REIS, A. Os valores salazaristas. In: (Org.). Portugal contemporâneo (1926-1958). Lisboa: Alfa, 1990a. v 4. p. 333-338.

A televisão: arma do poder e janela para o mundo. In: REIS, A. (Org.). Portugal contemporâneo (1958-1974). Lisboa: Alfa, 1990b. v 5. p. 203-206.

RODRIGUES, S. From vaginal exception to exceptional vagina: the biopolitics of female genital cosmetic surgery. Sexualities, v. 15, n. 7, p. 778-794, 2012.

SAMPAIO, Sérgio. Magazine Semanário Feminino, n. 51, p. 26-27, 25 de novembro de 1967.

SANT'ANNA, D. B. Corpos de passagem: ensaios sobre a subjetividade contemporânea. São Paulo: Estação Liberdade, 2001.

SCHMIDT, L. A evolução da imagem pública da juventude portuguesa: 1974-1984. Análise Social, v. 21, n. 87-89, p. 1053-1966, 1985.

SEALE, C.; CAVERS, D.; DIXON-WOODS, M. Commodification of body parts: by medicine or by media? Body \& Society, v. 12, n. 1, p. 25-42, 2006.

SHARP, L. A. The commodification of the body and its parts. Annual Review of Anthropology, n. 29, p. 287-328, 2000.

SHEPER-HUGUES, N. Bodies for sale - whole or in parts. In: SHEPER-HUGUES, N.; WACQUANT, L. Commodifying Bodies. Londres: SAGE, 2001. p. 1-8. 